\title{
Techno-Economic and Environmental Assessment for Biomethane Production and Cogeneration Scenarios From OFMSW In Mexico
}

\section{Omar Anaya-Reza}

Universidad Nacional Autónoma de México: Universidad Nacional Autonoma de Mexico https://orcid.org/0000-0003-4961-5578

\section{María Fe Altamirano-Corona}

Universidad Nacional Autónoma de México: Universidad Nacional Autonoma de Mexico https://orcid.org/0000-0001-9485-8566

\section{Gabriel Castelan-Rodríguez}

Universidad Nacional Autónoma de México: Universidad Nacional Autonoma de Mexico https://orcid.org/0000-0002-4967-3834

\section{Sergio Adrian García-González}

Universidad Nacional Autónoma de México: Universidad Nacional Autonoma de Mexico https://orcid.org/0000-0002-0544-1724

\section{Alfonso Durán-Moreno ( $\nabla$ alfdur@unam.mx )}

Universidad Nacional Autonoma de Mexico https://orcid.org/0000-0002-0419-2391

\section{Research Article}

Keywords: OFMSW treatment, Anaerobic digestion, Biomethane, Energy generation, Techno-Economic analysis, Potential environmental index.

Posted Date: May 28th, 2021

DOl: https://doi.org/10.21203/rs.3.rs-529330/v1

License: (c) (1) This work is licensed under a Creative Commons Attribution 4.0 International License. Read Full License

Version of Record: A version of this preprint was published at Waste and Biomass Valorization on October 8th, 2021. See the published version at https://doi.org/10.1007/s12649-021-01592-x. 


\section{Abstract}

Mexico City is one of the largest cities in the world and therefore there is a high generation of waste, of which $44 \%$ is equivalent to the Organic Fraction of Municipal Solid Waste (OFMSW). In this work, two case studies are evaluated for the application of biogas obtained in an anaerobic digestion process using OFMSW. CASE I considers obtaining biomethane, while CASE II considers energy cogeneration. The biogas yield was determined and was used to carry out an analysis of the process through an economic and environmental impact evaluation on different amounts of OFMSW (100-500 MT). The net present value of this project does not show the feasibility of the process, unless subsidy support is considered. The value of the smallest subsidy over the total investment to find NPV $=0$, is $5.64 \%$ for CASE I and $6.84 \%$ for CASE II at 200 MT of OFMSW. The WAste Reduction (WAR) methodology was used, which shows that the potential for environmental impact for the two cases is only $4 \%$. The in-depth research of this work helps to maintain the anaerobic digestion process in a circular economy context, for the supply of energy and the protection of the environment.

\section{Full Text}

This preprint is available for download as a PDF.

\section{Figures}

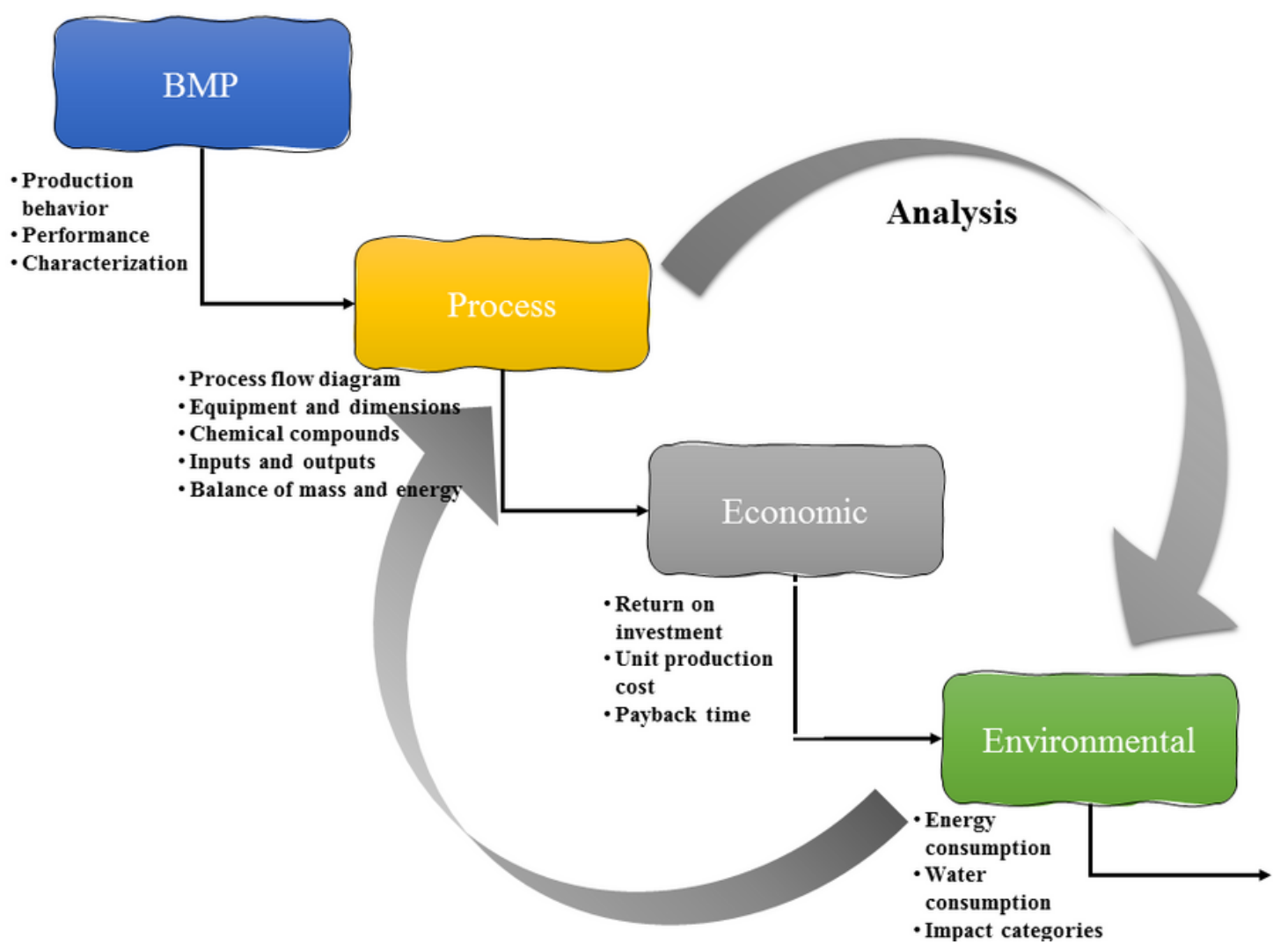

Figure 1 
Methodological strategy for the comprehensive study of the anaerobic digestion process

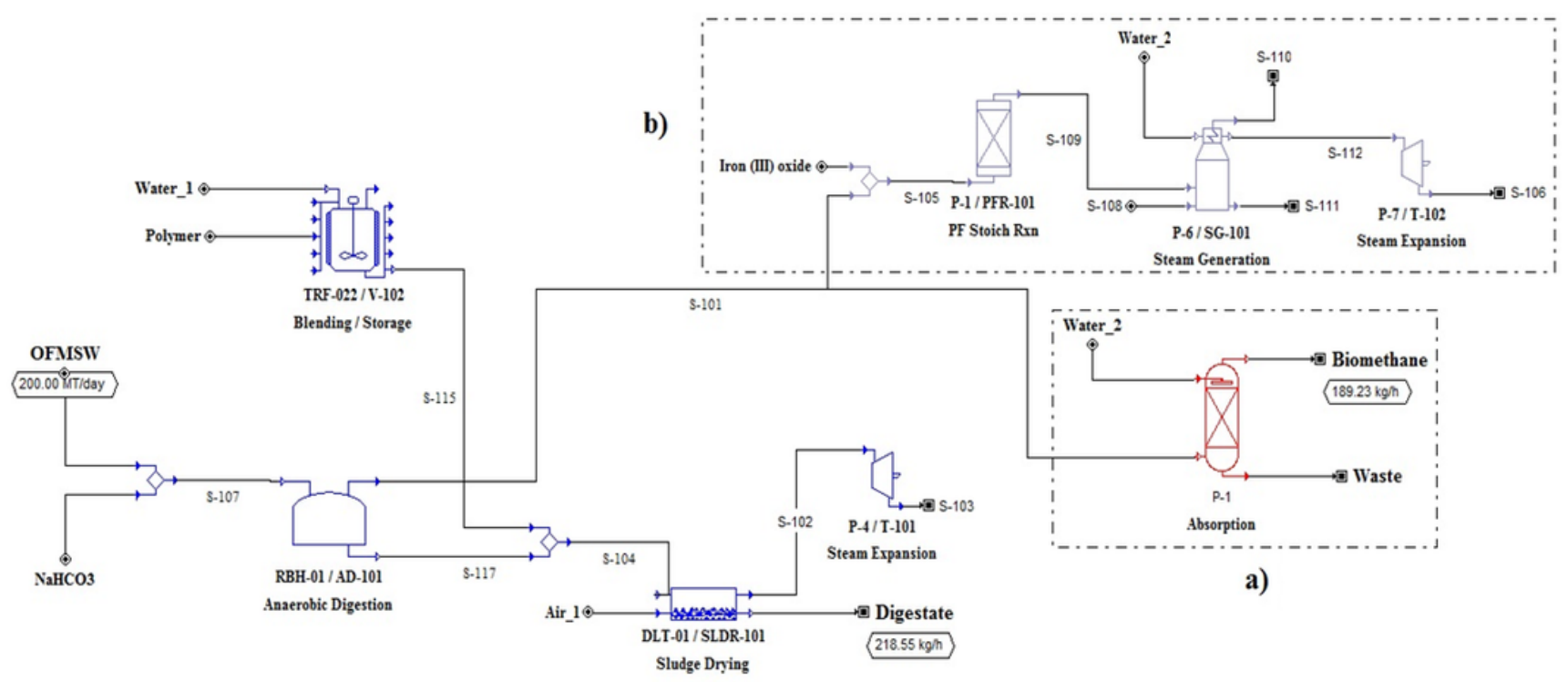

Figure 2

Flowsheet representing the process of anaerobic digestion for a) CASE I and b) CASE II

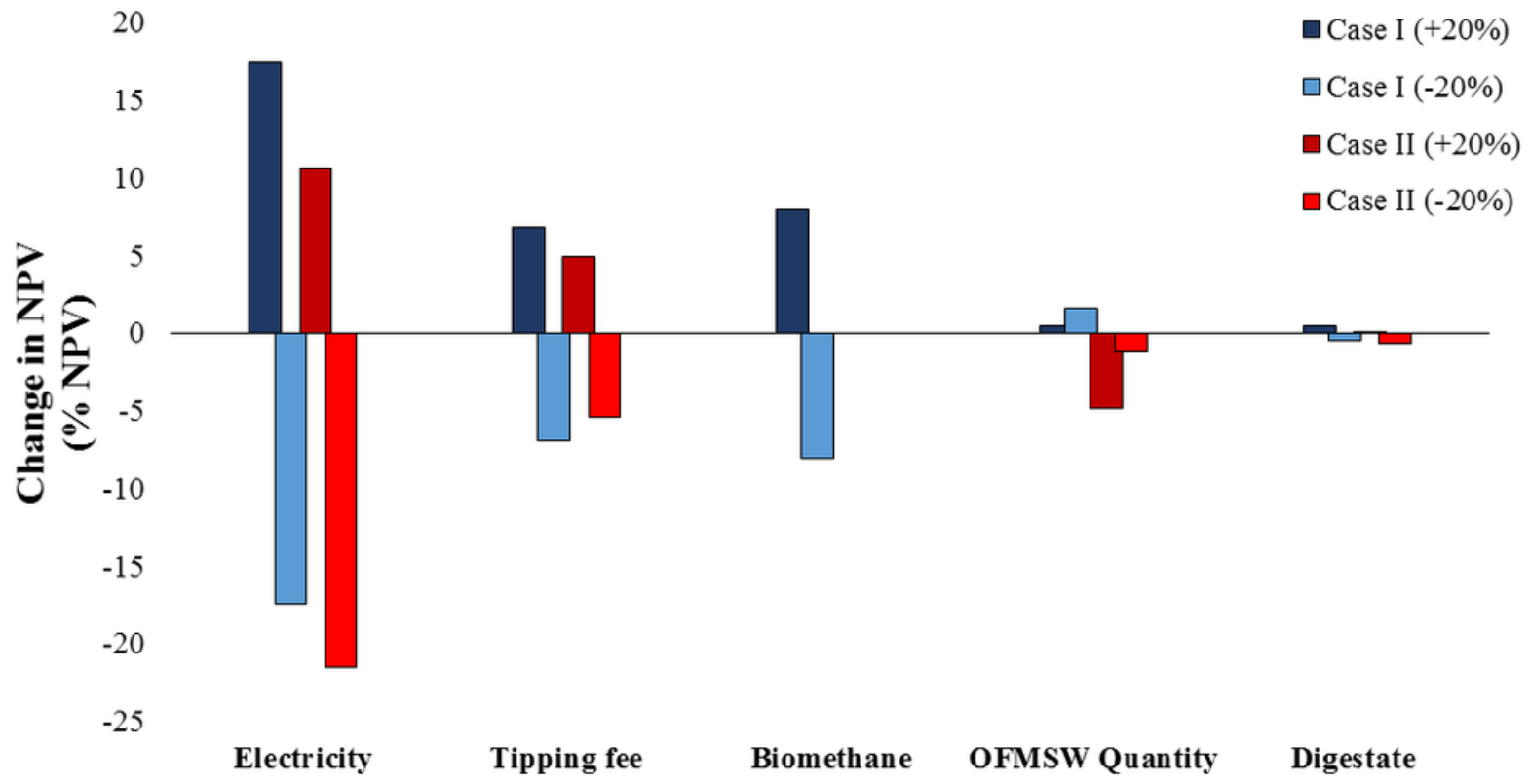


Figure 3

Sensitivity analysis showing the effect of the variables used in ADP on NPV for a) CASE I and b) CASE II

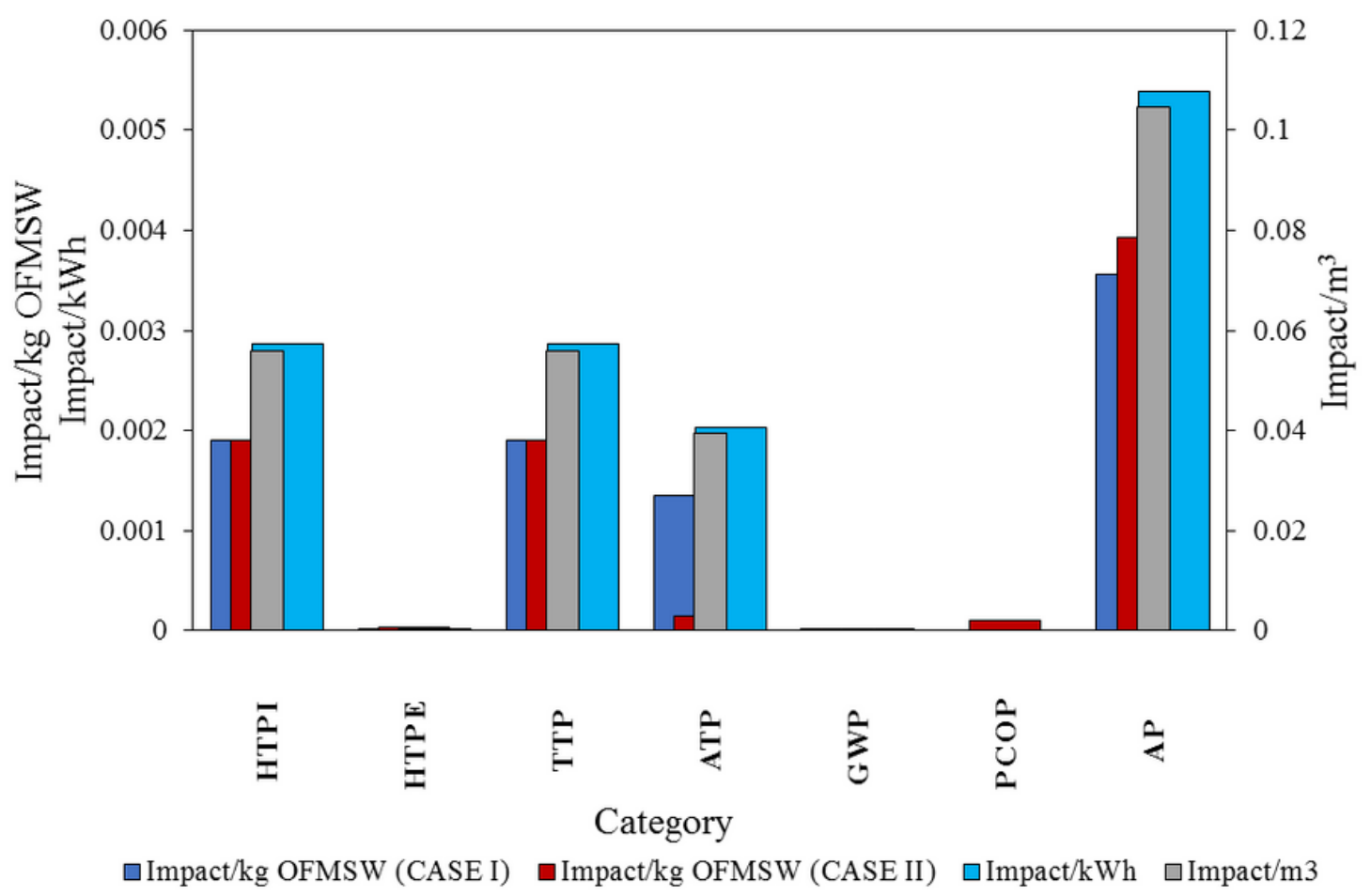

\section{Figure 4}

Environmental impact index by amount of OFMSW treated, volume of biomethane produced and electricity generated. 


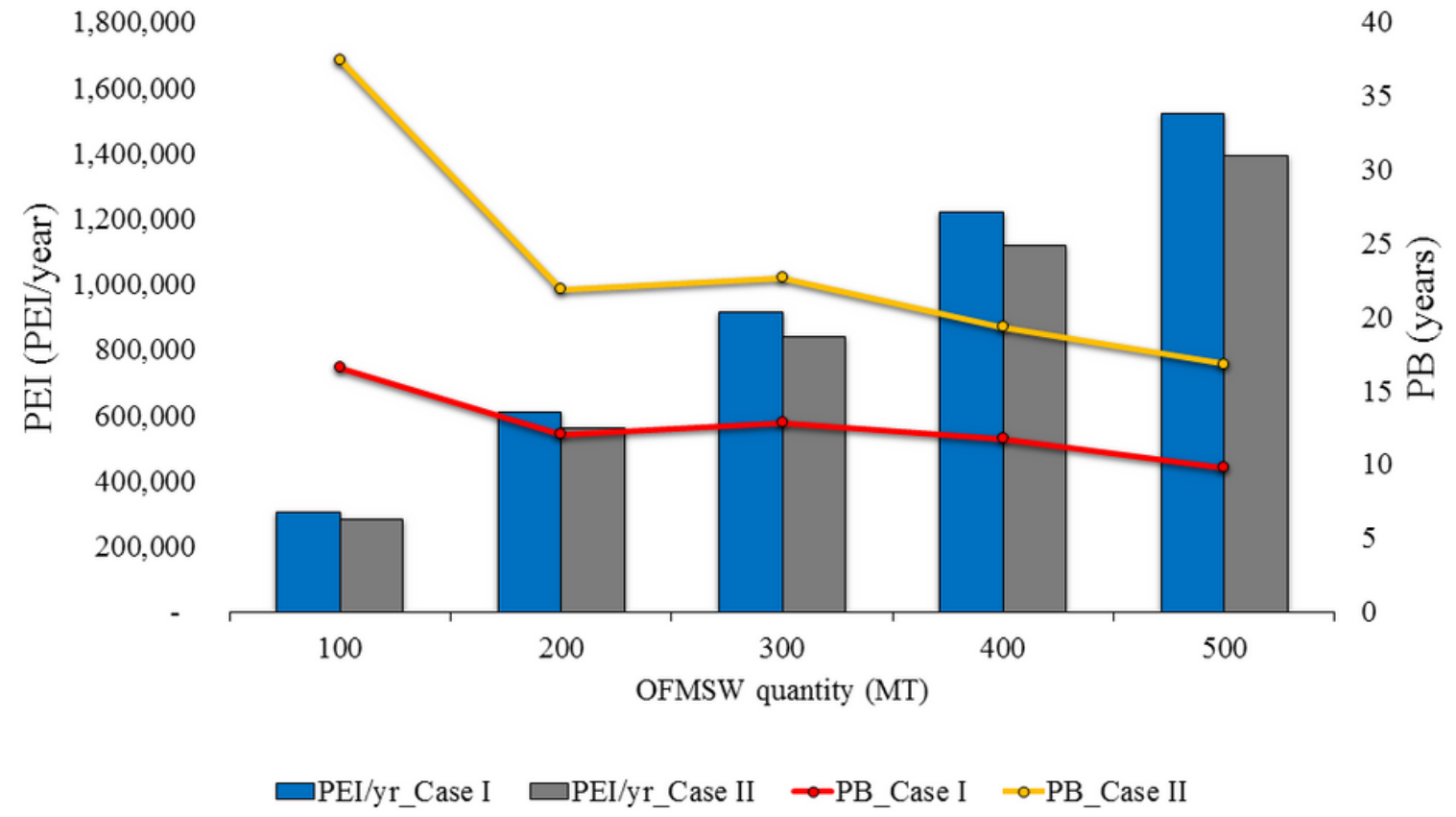

Figure 5

Comprehensive evaluation of ADP for CASE I and CASE II

\section{Supplementary Files}

This is a list of supplementary files associated with this preprint. Click to download.

- Graphicalabstract1.tif 